\title{
Supine volume drop and diaphragmatic function in adults with Pompe disease
}

\section{To the Editors:}

The onset of the adult form of Pompe disease, also known as acid maltase deficiency or glycogen storage disease type II, is a slow progressive muscular disorder in which little correlation exists between respiratory function and locomotor function [1]. The greater degree of respiratory dysfunction, compared with mobility loss, is mainly ascribable to the predominant and progressive involvement of the diaphragm [1].

The prominent diaphragmatic dysfunction in Pompe disease, together with the recent introduction of enzyme replacement therapy in adults, indicate a need for clarifying respiratory outcomes in adult-onset Pompe disease [2]. An international database of medical information on patients with Pompe disease has been set up by Genzyme Corporation (Cambridge, MA, USA), a manufacturer of replacement enzymes (www. pomperegistry.com). The only parameter recommended in the Genzyme Pompe registry for assessing diaphragmatic function is vital capacity (VC) in the upright position. However, it has been demonstrated in a population of patients with suspected diaphragmatic weakness that the supine VC drop provided a good estimate of diaphragmatic dysfunction [3-5]. The aim of the current study was to determine the relationship between invasive diaphragmatic indices and noninvasive respiratory function variables in patients with adult-onset Pompe disease.

We retrospectively retrieved data from the clinical files of patients with adult-onset Pompe disease at the respiratory laboratory of the Raymond Poincaré Teaching Hospital (Garches, France) between 2002 and 2010 for diaphragmatic muscle evaluation. Our study was approved by the French Commission Nationale de l'Informatique et des Libertés in accordance with current French legislation.

Lung and respiratory muscle function were evaluated with noninvasive and transdiaphragmatic pressure $(P \mathrm{di})$ measurements, performed on two different days. Pulmonary function testing was performed with a SensorMedics Vmax 229 (Yorba Linda, CA, USA) according to standard guidelines in the upright and supine positions and reported as per cent predicted [6]. Maximal sniff nasal inspiratory pressure (SNIP) and maximal inspiratory pressure $(P \mathrm{I}, \mathrm{max})$ were measured from the functional residual capacity (FRC) in the upright position. Maximal expiratory pressure $(P E, \max )$ was measured at the total pulmonary capacity. The highest value of each measurement method was used. Pdi was measured as the difference between gastric and oesophageal pressures recorded using a catheter-mounted pressure-transducer system (Gaeltec, Duncegan, UK). Cervical magnetic phrenic nerve stimulation via a $90-\mathrm{mm}$ circular coil powered by a Magstim stimulator (Magstim 200²; The Magstim Limited Company, Whitland, UK) was used to determine twitch Pdi (Pdi,tw). All magnetic stimulations were applied at FRC. Mean $P$ di,tw was calculated from at least five phrenic nerve stimulations, at maximal power output, in order to achieve supramaximal stimulation [7]. Pdi was also measured during sniff manoeuvers $(P$ di,sniff $)$ and maximal inspiratory manoeuvers $P$ di,max.

Correlations were sought between $P$ di parameters and other respiratory function parameters (upright and supine $\mathrm{VC}$, upright and supine inspiratory capacity (IC), upright expiratory reserve volume (ERV), PI,max, SNIP, and PE,max. Univariate analysis was used to evaluate the contribution of each variable. The significance level was set at $5 \%$.

Between 2002 and 2010, 30 patients with stable adult-onset Pompe disease were referred to our respiratory laboratory. All patients had low acid $\alpha$-glucosidase activity in circulating leukocytes and known gene mutations. 16 patients were receiving mechanical ventilation; five patients had a tracheotomy. SNIP was not measured in these last patients, as the presence of the tracheostomy tube would have altered the result, and PI,max was measured at the level of the sealed tracheostomy tube. Of the 16 mechanically ventilated patients, five (including two with tracheostomies) refused supine spirometry, because they were not able to tolerate the supine position without mechanical ventilation. Therefore, only $P \mathrm{I}, \max , P$ E,max and upright spirometry (ERV, IC, and VC) were available for all 30 patients. The median VC in upright position was $51 \%$ and the interquartile range was $32-67 \%$. The median $P$ di,sniff was $19 \mathrm{cmH}_{2} \mathrm{O}$ (interquartile range 5-29 $\mathrm{cmH}_{2} \mathrm{O}$ ).

\begin{tabular}{|c|c|c|c|c|c|c|c|}
\hline \multirow[t]{3}{*}{ TABLE 1} & \multicolumn{7}{|c|}{$\begin{array}{l}\text { Univariate regression analysis of } \\
\text { transdiaphragmatic pressure }(P \mathrm{di}) \text { swings during } \\
\text { sniff manoeuvers }(P \mathrm{di} \text {,sniff), maximal inspiratory } \\
\text { manoeuvers }(P \text { di,max }) \text { and twitch }(i . e . \text { magnetic } \\
\text { phrenic nerve stimulation) } P \text { di }(P \text { di,tw) on other } \\
\text { noninvasive variables }\end{array}$} \\
\hline & \multirow[t]{2}{*}{ Patients $\mathrm{n}$} & \multicolumn{2}{|r|}{ Pdi,sniff } & \multicolumn{2}{|c|}{ Pdi,max } & \multicolumn{2}{|r|}{$P d i, t w$} \\
\hline & & $r^{2}$ & $\mathrm{p}$-value & $r^{2}$ & $p$-value & $r^{2}$ & p-value \\
\hline Upright VC & 30 & 0.605 & $<0.0001$ & 0.640 & $<0.0001$ & 0.484 & $<0.0001$ \\
\hline Supine Vc & 25 & 0.556 & $<0.0001$ & 0.538 & $<0.0001$ & 0.716 & $<0.0001$ \\
\hline Upright IC & 30 & 0.520 & $<0.0001$ & 0.627 & $<0.0001$ & 0.522 & $<0.001$ \\
\hline Supine IC & 25 & 0.616 & $<0.0001$ & 0,666 & $<0.0001$ & 0.701 & $<0.001$ \\
\hline$P I, \max$ & 30 & 0.623 & $<0.0001$ & 0.608 & $<0.0001$ & 0.545 & $<0.0001$ \\
\hline SNIP & 25 & 0.481 & 0.0001 & 0.350 & $<0.002$ & 0.276 & 0.007 \\
\hline Upright ERV & 30 & 0.335 & 0.0008 & 0.281 & 0.0013 & 0.283 & 0.0025 \\
\hline$P_{E, \max }$ & 30 & 0.275 & 0.003 & 0.315 & 0.0012 & 0.183 & $<0.02$ \\
\hline$\Delta \mathrm{VC} /$ upright VC & 25 & 0.103 & 0.12 & 0.066 & 0.22 & 0.199 & 0.015 \\
\hline$\Delta$ IC/upright IC & 25 & 0.269 & 0.008 & 0.221 & 0.017 & 0.353 & 0.002 \\
\hline
\end{tabular}


Table 1 reports the results of the univariate regression analysis of invasive and noninvasive variables. All the directly measured noninvasive variables correlated with the invasive variables. According to the type of $P$ di index, the closest correlation was with either $P \mathrm{I}$,max or upright or supine volumes (VC or IC). The correlations were weak with variables relating to expiratory muscle function $(P \mathrm{E}, \max$ and $\mathrm{ERV})$ and were not always significant for variables assessing differences between the supine and upright positions.

In patients with adult-onset Pompe disease, $P$ di indices correlated to all directly measured noninvasive parameters, including those evaluating the expiratory muscles, whereas they poorly correlated or did not correlate with supine VC and IC drops.

In the supine position, the hydrostatic forces displace a weakened diaphragm cranially, thus reinforcing the sucking effect of the ribcage's inspiratory muscles on a weakened diaphragm. The result is a marked decrease in lung volumes in the supine position of patients with a diaphragmatic weakness [3]. Accordingly, in a few studies of patients with various neuromuscular disorders and various degrees of a diaphragmatic weakness, $P$ di values correlated with the supine fall in VC [4-5]. Here, our patients with adult-onset Pompe disease had abnormal drops in both VC and IC in the supine position, but these drops did not correlate consistently or closely with the $P$ di indices. Similarly, a study of patients with amyotrophic lateral sclerosis showed no correlation between the supine VC drop and Pdi,sniff [8]. One possible explanation for the discrepancy involves the difference in body mass index (BMI). However, in our study, BMI was not significantly associated with the VC drop $\left(r^{2}=0.1\right)$ or IC drop $\left(r^{2}=0.028\right)$. Another hypothesis is that abdominal muscle dysfunction may alter upright VC and IC, thus masking the deleterious effect of the supine position in patients with a diaphragmatic weakness. Abdominal muscle weakness without diaphragmatic weakness, as observed in spinal cord injury, increases abdominal compliance and promotes descent of the diaphragm in the upright position with a proportional decrease in the area of apposition of the diaphragm to the ribcage, which impairs the ability of the diaphragm to elevate the ribcage [9]. In contrast, the supine position places the diaphragm in a more advantageous position for ventilation [9]. The weak, but significant, correlations linking $P$ di to $P$ E,max and ERV in our patients suggests a relationship between diaphragmatic weakness and expiratory muscle weakness in adult-onset Pompe disease. Furthermore, during Pdi measurements, gastric pressure during coughing, considered the best parameter for assessing expiratory muscle function [10], correlated more closely with Pdi,sniff $\left(\mathrm{r}^{2}=0.36 ; \mathrm{p}<0.0005\right)$ and $P$ di,max $\left(\mathrm{r}^{2}=0.46 ; \mathrm{p}<0.0001\right)$ than did PE,max or ERV. Whereas the supine drops in VC and IC increase with the degree of diaphragmatic weakness, greater weakness of the abdominal expiratory muscles may have the opposite effect. Finally, the observed relationship between diaphragmatic weakness and expiratory muscle weakness may explain the absent or weak negative correlations between Pdi indices and supine drops in VC and IC.

We demonstrated that $P$ di indices correlated with all spirometry volumes and noninvasive maximal pressures, including those which evaluated expiratory muscles. According to the type of $P$ di index, the closest correlation was with either PI,max or upright or supine volumes (VC or IC). In contrast, volume drops between the upright and supine positions, previously suggested as markers for diaphragmatic dysfunction, were unreliable, probably because concomitant expiratory muscle dysfunction altered their relationships with diaphragmatic dysfunction. Finally, upright VC remains a strong indicator in the followup of respiratory function in adults with Pompe disease.

\section{Hélène Prigent*, David Orlikowski*, Pascal Laforêt", Nadège Letilly*, Line Falaize*, Nadine Pellegrini*, Djillali Annane*, Jean-Claude Raphael ${ }^{*}$ and Frédéric Lofaso*, *Dept of Physiology-Functional Testing, Intensive Care Unit, and CIC-IT 805, Raymond Poincaré Teaching Hospital, AP-HP, Garches, "Institut de Myologie, Hôpital Pitié-Salpêtrière, Paris, and "Inserm UMR955, Créteil, France.}

Correspondence: F. Lofaso, Service de Physiologie-Explorations Fonctionnelles, Hôpital Raymond Poincaré, 92380 Garches, France. E-mail: f.lofaso@rpc.aphp.fr

Statement of Interest: None declared.

Acknowledgements: We would like to thank K. Laloui (Institut de Myologie, Hôpital Pitié-Salpêtrière, Paris, France) who participated in the Walton score evaluation.

\section{REFERENCES}

1 Pellegrini N, Laforet P, Orlikowski D, et al. Respiratory insufficiency and limb muscle weakness in adults with Pompe's disease. Eur Respir J 2005; 26: 1024-1031.

2 van der Ploeg AT, Clemens PR, Corzo D, et al. A randomized study of alglucosidase alfa in late-onset Pompe's disease. $N$ Engl J Med 2010; 362: 1396-1406.

3 Davis J, Goldman M, Loh L, et al. Diaphragm function and alveolar hypoventilation. Q J Med 1976; 45: 87-100.

4 Mier-Jedrzejowicz A, Brophy C, Moxham J, et al. Assessment of diaphragm weakness. Am Rev Respir Dis 1988; 137: 877-883.

5 Fromageot C, Lofaso F, Annane D, et al. Supine fall in lung volumes in the assessment of diaphragmatic weakness in neuromuscular disorders. Arch Phys Med Rehabil 2001; 82: 123-128.

6 Quanjer PH, Tammeling GJ, Cotes JE, et al. Lung volumes and forced ventilatory flows. Eur Respir J 1993; 6: Suppl. 16, 5-40.

7 Wragg S, Aquilina R, Moran J, et al. Comparison of cervical magnetic stimulation and bilateral percutaneous electrical stimulation of the phrenic nerves in normal subjects. Eur Respir J 1994; 7: 1788-1792.

8 Lechtzin N, Wiener CM, Shade DM, et al. Spirometry in the supine position improves the detection of diaphragmatic weakness in patients with amyotrophic lateral sclerosis. Chest 2002; 121: 436-442.

9 Brown R, DiMarco AF, Hoit JD, et al. Respiratory dysfunction and management in spinal cord injury. Respir Care 2006; 51: 853-868.

10 Man WD, Kyroussis D, Fleming TA, et al. Cough gastric pressure and maximum expiratory mouth pressure in humans. Am J Respir Crit Care Med 2003; 168: 714-717.

DOI: $10.1183 / 09031936.00169011$ 